\title{
Antibiogram and Biofilm Phenotypic Characterization of $E$. coli Isolates from Milk and Environmental Sources
}

\author{
Bobade Sumedha*, R.M. Gade, S. Rajurkar, A. Raut, P. Uike and A. Bhoyar \\ Vasantrao Naik College of Agricultural Biotechnology, Yavatmal (M.S.), India \\ *Corresponding author
}

\begin{tabular}{|l|}
\hline Ke y w o r d s \\
Antibiogram, \\
Antibiotic, Biofilm, \\
Environment, \\
Resistance
\end{tabular}

\section{Introduction}

Escherichia coli is an important pathogen in bovine, capable of causing intestinal and extra intestinal infections which constitute a public health hazard. Environmental survival of Escherichia coli may play an important role in the persistence and dissemination of this organism on farms. Cattle are an important reservoir of $E$. coli organisms. Infection may also occur through consumption of unpasteurized milk and other foods, personto-person transmission and direct contact with infected cattle or their manure (Rahn et al., 1997). E. coli is commensal microbe which is the major part of normal aerobic microbial population of the intestine of humans and warm blooded animals. Its presence is considered as major indicator of faecal contamination in food and water (Karmali et al., 2010). There is strong evidence that the use of antimicrobials can lead to the appearance and rise of bacterial resistance both in human and animals. These are disseminated in environment such as farm animals and derived foods, domestic and even 
in wild animals, healthy humans, waste water, vegetables and other sources (Ben Sallem et al., 2011). Attachment of pathogenic bacteria to food contact surfaces and the subsequent biofilm formation represent a serious threat to the food industry, since these bacteria are more resistant to antimicrobials or possess more virulence factors (Pavlickova et al., 2017)

Ability to adhere to different surfaces, and formed biofilms have been important features associated with $E$. coli virulence (Bello et al., 2013). Additionally, resistance to antimicrobials in biofilm-forming isolates contributes to bacterial persistence which may lead to chronic infections and treatment problems (Cergole-Novella et al., 2015).

As a matter of fact, E. coli from livestock is exposed to a great selective pressure because in some countries, more than half of the antimicrobial agents are used in foodproducing animals. Antibiotics have helped in reducing diseases in animal husbandry; however, there is a growing awareness of public health concerns associated with the use of antibiotics. Antibiotic is widely used to protect the infectious diseases caused by $E$. coli. More uses of antimicrobial agents are believed to enhance resistance of bacteria and it may contribute to antimicrobial agent resistance in humans acquired through the food chain. Therefore the disk diffusion method can be used to study the resistivity pattern of E. coli (Guerra et al., 2003). Several mechanism have been proposed to explain this high resistance of Biofilm including restricted penetration of antimicrobial agent into Biofilms, slow growth owing to nutrient limitation, expression of genes involved in general stress response and emergence of Biofilm specific phenotypes (Ito et al., 2009).

Bacterial biofilm cause chronic infection because they show increased tolerances to antibiotics and disinfectant chemicals as well as other component of the body defence system (Hoiby et al., 2010). The Congo Red Agar method is fast, reproducible, and presents an advantage that the colonies remain viable in the medium for further analysis. Therefore the method was chosen in an attempt to improve its ability to identify biofilm production of $E$. coli. There are fair chances of contamination from animal product with intestinal of fecal of animals there may serve as a source of infection of human being. Thus, it is an important to study pathogenic characteristic of $E$. coli of animal origin.

The main aim of this study was to isolate and characterize $E$. coli and to investigate the correlation between antibiotic resistance against 6 antibiotics, and biofilm formation in E. coli recovered from bovine and their farm environment, according to their origin.

\section{Materials and Methods}

A total of 64 samples from 10 different sources viz. soil (5), fecal (11), manure (7), drainage (2), drinking water (6), tap water (2), fodder- dry fodder (12) and green fodder (4), cotton seed cake (6), milk (9) samples were collected in sterile container, labeled and transported to the laboratory for analysis. The samples were stored in cold condition for further analysis.

The isolation and identification of $E$. coli were performed as per the guidelines of Cowan and Steel (1970) and Cruickshank et al., (1975) and Rappaport et al., (1953). The isolates were further confirmed by biochemical reaction.

\section{Biofilm production on congo red agar plate}

The isolates were further analyzed for biofilm production on Congo red medium, prepared as per the Berkhoff and Vinal (1986) and E. coli isolates were streaked on the CR medium 
and incubated at $37^{\circ} \mathrm{C}$ for 3 days. The colonies were examined daily for color change. The E. coli isolates which produced intense orange or brick red colonies were considered as $\mathrm{CR}$ positive and those which produced grayish white colonies and remained so throughout the incubation period were recorded as $\mathrm{CR}$ negative.

\section{Antibiotic sensitivity tests}

Antimicrobial susceptibility testing was done by the disc diffusion method using MuellerHinton agar (Hi Media Laboratories, Mumbai, India).

Susceptibility of $E$. coli isolates to 6 commercially available antimicrobial disk was determined following disc diffusion method (Bauer et al., 1966). The antimicrobial agent used as ampicillin (AMP), tetracycline (TE), streptomycin (S), gentamycin (GEN), chloramphenicol (C), ciprophloxacin (CIP).

\section{Results and Discussion}

The present study was undertaken to investigate comparison between antibiotic sensitivity test and biofilm production among E. coli isolated from bovine origin.

\section{Prevalence of $E$. coli}

Out of 64 samples collected $34(53.12 \%)$ isolates were identified as E. coli (Table 1). The confirmed isolates were screened for biofilm production and Antibiotic resistivity pattern.

Congo red agar test (CRA) was used to differentiate invasive and non invasive $E$. coli. In the present study $E$. coli isolates were screened for biofilm production on $0.3 \%$ Congo Red agar. Out of 34 isolates 16 were found to be biofilm producer on congo red (Table 2).

Out of 34 samples $18 \mathrm{E}$. coli isolates were studied for Antibiotic Sensitivity Test. Eighteen $E$. coli isolates from various sources were tasted against 6 antibiotics. The highest resistance was found for tetracycline (66\%) and ampicillin (66\%). The isolates were susceptible to some antibiotics like Chloramphenicol (77.78\%), Ciproflloxacin (77.78\%), Streptomycin (88.89\%). All isolates were sensitive to Gentamycin. The different antibiotic patterns have been observed (Figure 1). The highest resistivity pattern reported in tetracycline and lowest in streptomycin and no resistance in Gentamycin.

Table.1 Frequency of prevalence of E. coli isolated

\begin{tabular}{|l|l|c|c|}
\hline Sr.No & $\begin{array}{l}\text { Source } \\
\text { Soil }\end{array}$ & $\begin{array}{c}\text { No. of sample } \\
\text { collected }\end{array}$ & $\begin{array}{c}\text { No. of positive } \\
\text { sample }\end{array}$ \\
\hline $\mathbf{1 .}$ & Soil & 5 & 3 \\
\hline $\mathbf{2 .}$ & Fecal & 11 & 8 \\
\hline $\mathbf{3 .}$ & Manure & 7 & 3 \\
\hline $\mathbf{4 .}$ & Drainage & 6 & 1 \\
\hline $\mathbf{5 .}$ & Drinking water & 4 & 3 \\
\hline $\mathbf{6 .}$ & Green Fodder & 2 & 1 \\
\hline $\mathbf{7 .}$ & Tap water & 12 & 1 \\
\hline $\mathbf{8 .}$ & Dry fodder & 9 & 7 \\
\hline $\mathbf{9 .}$ & Milk & 6 & 6 \\
\hline $\mathbf{1 0}$ & Cotton seed Cake & $\mathbf{6 4}$ & $\mathbf{3 4}(\mathbf{5 3 . 1 2 \% )}$ \\
\hline Total & & &
\end{tabular}


Table.2 Summary of biofilm producing $E$. coli isolate

\begin{tabular}{|l|l|c|c|}
\hline Sr. No & Source & No. of isolate & $\begin{array}{c}\text { Biofilm } \\
\text { Production }\end{array}$ \\
\hline $\mathbf{1 .}$ & Soil & 3 & 1 \\
\hline $\mathbf{2 .}$ & Fecal & 8 & 6 \\
\hline $\mathbf{3 .}$ & Manure & 3 & 2 \\
\hline $\mathbf{4 .}$ & Drainage & 1 & 1 \\
\hline $\mathbf{5 .}$ & Drinking water & 3 & 1 \\
\hline $\mathbf{6 .}$ & Green Fodder & 1 & 1 \\
\hline $\mathbf{7 .}$ & Tap water & 1 & 1 \\
\hline $\mathbf{8}$ & Dry fodder & 7 & 2 \\
\hline $\mathbf{9 .}$ & Milk & 6 & 1 \\
\hline $\mathbf{1 0 .}$ & Cotton seed Cake & 1 & 0 \\
\hline Total & & $\mathbf{3 4}$ & $\mathbf{1 6}(\mathbf{4 7 . 0 5 \% )}$ \\
\hline & & & \\
\hline
\end{tabular}

Fig.1 Antibiotic resistivity pattern of E. coli isolates

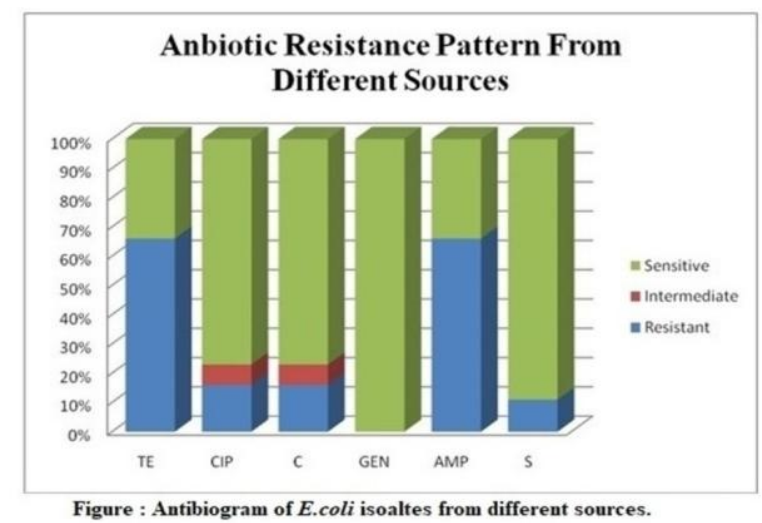

Out of 64 samples $34(53.12 \%)$ samples were confirmed as E. coli, whereas $16(47.05 \%)$ isolates were to be Biofilm producer on Congo red Agar. Thakre et al., (2016) recorded the overall prevalence of $E$. coli $(53.12 \%)$ isolated from fecal samples of cattle. Alam et al., (2013) reported an overall prevalence of $E$. coli of $69.23 \%$ with highest in the diarrhoeic stool sample $(91.61 \%)$ the finding from our study showed higher prevalence was found in fecal samples. The prevalence was observed to be $85.71 \%$ and
$20 \%$ of the fecal and soil samples (Parul et al., 2014), while in our study prevalence of $72.72 \%$ from fecal and $60 \%$ of soil was recorded.

The biofilm production study show positivity in $47.05 \%$ E. coli isolates. Thakrey et al., (2016) and Warke et al., (2017) reported $82.08 \%$ and $77.67 \%$ biofilm producer isolates of fecal and environmental samples from cattle farm on Congo red agar. Parul et al., 2014 recorded percent positivity of 
$44.28 \%$ for feces and $5 \%$ for soil was reported on Congo red dye assay while in our study it was found to be $54.5 \%$ and $20 \%$ respectively. The antibiogram of pathogenic strains showed high level of sensitivity to Ciprofloxacin (93\%), Gentamycin (89\%) and low level of sensitivity against Ampicillin (8\%) and Streptomycin (5\%). All isolates were 100\% resistant to Tetracycline while in this study the highest resistance was found for tetracycline $(66 \%)$ followed by ampicillin $(66 \%)$ and sensitive to Ciproflloxacin (77.78\%), Streptomycin (88.89\%), Gentamycin (100\%).

The multidrug resistance pattern among six antibiotics suggest the contribution to the spread of various drug resistance strains of $E$. coli. Tadesse et al., 2018 studied 24 raw cow milk samples from dairy farms $(27.91 \%)$ were found to be positive for $E$. coli and highly resistant to ampicillin (70\%), chloramphenicol (50\%), and kanamycin $(50 \%)$ and susceptible to gentamicin $(100 \%)$, tetracycline (60\%), and ciprofloxacin (90\%) from our study resistivity in Ampicillin and tetracycline (66\%), and susceptibility to chloramphenicol (77.78\%), Ciprofloxacin $(77.78 \%)$ and Gentamycin (100\%) was recorded the variation of multidrug resistance recorded in the current study might be due to biofilm production and high antimicrobial use in dairy cattle.

In our study high prevalence, biofilm production and resistivity pattern was found in fecal sample. Animal feces are potential source of antibiotic resistant bacteria. If released into the environment, resistant strains may contaminate water and food sources and can be a potential threat to human health (Roy et al., 2009). Nsofor and Iroegbu, (2013) reported resistant rate of $100 \%$ to Gentamycine, $89 \%$ streptomycin, $77 \%$ to chloramphenicol, 34\% to ampicillin, $34 \%$ tetracycline. The results of this study showed highest resistivity to Ampicillin (66\%) and lowest to streptomycin (11\%), Chloramphenicol (16\%) and $100 \%$ sensitivity to Gentamycin.

Multiple antibiotic resistant strains can be transported from animals to humans by food chain represents public health hazard due to the fact that foodborne outbreaks would be difficult to treat.

In conclusion, the findings of this study suggest that biofilm producing strains of $E$. coli from milk and environmental samples from cattle farm can be an important reservoir for various multidrug resistant determinants. The presence of foodborne pathogens in milk can be due to direct contact with contaminated sources in the dairy farm environment and to excretion from the udder of an infected animal. The presence of pathogenic E. coli are of prime importance due to their public health implications, which enter into the food chain through the consumption of contaminated milk or through farm runoff water, soil which greatly influenced by the application of manure. Antimicrobial resistance is more common in biofilm forming $E$. coli and can be a source of transferring antimicrobial resistant bacteria to human. Biofilm production is a common phenomenon and it is one of the important mechanisms of antimicrobial resistance among the foodborne pathogen. Antimicrobial resistance is more common in biofilm forming E. coli and can be a source of transferring antimicrobial resistant bacteria to human. Bacteria gradually become resistant to routinely used antibiotics may also lead to a failure of antimicrobial therapy. Antimicrobial resistance is a global health concern in both human and animals. Therefore there is need of implementation of effective hygienic measures for food safety at farm level as well as steps must be taken to control the overuse of antibiotics. 


\section{References}

Alam, M J, Rahman, M P, Siddique, M F R Khan and Rahman. M B. (2010). Antibiogram and plasmid profiling of E. coli isolates. Int. J. BioRes. 1(3): 01-07.

Bauer, A.W. Kirby, W.M.M., Sheris, Jc. and M. Truck. (1966). Antibiotic susceptibility testing by a standardized single disk method. Am J Clin Pathol. 145: 225-230.

Bello, B.K, Adebolu, T.T and Oyetayo, V.O. (2013). Antibiogram and plasmid profile of Escherichia coli isolates in Well Water In Akure, South Western Nigeria. IOSR Journal Of Pharmacy. 3(7): 30-37.

Ben Sallem, R., Ben Slama, K., Estepa, V., Jouini, A., Gharsa, H., Klibi, N., Sáenz, Y., Ruiz Larrea, F., Boudabous, A. and Torres, C. (2011) Prevalence and characterisation of extended-spectrum beta-lactamase (ESBL)-producing Escherichia coli isolates in healthy volunteers in Tunisia. Eur. J. Clin. Microbiol. Infect. Dis. 31: 1511-1516.

Berkhoff, H.A., and A.C. Vinal (1986). Congo red medium to distinguish between invasive and non-invasive $E$. coli pathogenic for poultry. Avian Dis. 30: 117-121.

Cergole-Novella M., Pignatari, A. and Guth B., (2015) Adhesion, biofilm and genotypic characteristics of antimicrobial resistant Escherichia coli isolates. Brazilian Journal of Microbiology. 46(1): 167-171.

Cowan, S.T. and K.J. Steel (1970). Manual for the identification of Medical Bacteria. The Syndics of the Cambridge Univ. Press, Bentley House 200, Euston Road, London, U.K

Cruickshank, R., J.P. Duguid, B.P. Marmoin and R.H.A. Swain (1975). Medical Microbiology: 2, $12^{\text {th }}$ edn. Churchill Livingstone, Edinburgh, London and New York.

Guerra, B., Avsaroglu, M. D., Junker, E., Schroeter, A., Beutin, L., and Helmuth, R. (2007). Detection and characterisation of ESBLs in German Escherichia coli, isolated from animal, foods, and human origin between 2001-2006. Int. J. Antimicrob. Agents 29(2): 270-271.

Hoiby N., Djarnsholt T., Givskov N., Molin S., Ciofu O., Antibiotic resistance of bacterial biofilm (2010). Internationl J. of Antimicrobial Agents. 35 (4):322332.

Ito A., Taniuchi A.,May T.,Kawata K. and Okabe S., (2009). Increased Antibiotics Resistance Of Escherichia coli in Mature Biofilms. Appl. Environ. Microbiol. 75: 4093-4100.

Karmali, M.A., Gannon, V. and Sargeant, J.M. (2010) Verocytotoxin-producing (VTEC).Vet Microbiol.140: 360-370.

Nsofor C.A. and Iroegbu C.U. (2013). Antibiotic Resistance Profile of Escherichia coli Isolated from Five Major Geopolitical Zones of Nigeria. J. Bacteriol. Res. 5(3):29-34.

Parul, Basanti Bist, Barkha Sharma and Udit Jain (2014) Virulence associated factors and antibiotic sensitivity pattern of Escherichia coli isolated from cattle and soil. Veterinary World 7(5): 369-372.

Pavlickova S., Klancnik A., Dolezalova M., Mozina S.S. and Holko I., (2017) Antibiotic resistance, virulence factors and biofilm formation ability in Escherichia coli strains isolated from chicken meat and wildlife in the Czech Republic. J. Environ Sci Health 52(8):570-57.

Rahn K., Renwick S. A., Johnson R. P., Wilson J. B., Clarke R. C., Alves D., 
Mcewen S., Lior H. and Spika J. (1997) Persistence of Escherichia coli O157:H7 in dairy cattle and the dairy farm environment. Epidemiol. Infect., 119:251-259.

Rappaport F. and Sark G.J. (1953) Culture medium to determine motility and to differentiate intestinal pathogens. Am.J.Clin.Pathol. 23:948.

Roy K, Lebens M, Svennerholm A, and Teneberg S (2009). Enterotoxigenic Escherichia coli EtpA mediates adhesion between flagella and host cells. Nature 457: 594-598.

Tadesse H. A., N. B. Gidey, K. Workelule, H. Hailu, S. Gidey, A. Bsrat, and $\mathrm{H}$. Taddele (2018) Antimicrobial
Resistance Profile of E. coli Isolated from Raw Cow Milk and Fresh Fruit Juice in Mekelle, Tigray, Ethiopia. Veterinary Medicine International, 17.

Thakre T., Warke S., Bobade. S and D.R. Kalorey. (2016). Characterization of E. coli pathotypes of bovine and livestock farm environment origin. Indian J. Anim. Res., 1-5.

Warke, S., Bobade, S., and Ingle, V. (2017). Isolation and Molecular Characterization of ETEC and NTEC Escherichia coli from cattle farm with reference to virulence marker gene. Int. J. Liv. Res., 7(10): 1-7.

\section{How to cite this article:}

Bobade Sumedha, R.M. Gade, S. Rajurkar, A. Raut, P. Uike and Bhoyar, A. 2019. Antibiogram and Biofilm Phenotypic Characterization of E. coli Isolates from Milk and Environmental Sources. Int.J.Curr.Microbiol.App.Sci. 8(03): 2322-2328.

doi: https://doi.org/10.20546/ijcmas.2019.803.275 